\title{
Dendritic cells and macrophages are essential for the retention of lymphocytes in (peri)-insulitis of the nonobese diabetic mouse: a phagocyte depletion study
}

\author{
Tatjana Nikolic ${ }^{1,2, *}$, Sacha B Geutskens ${ }^{1, *}$, Nico van Rooijen ${ }^{3}$, Hemmo A Drexhage ${ }^{1}$ \\ and Pieter JM Leenen ${ }^{1}$ \\ ${ }^{1}$ Department of Immunology, Erasmus MC, Rotterdam, The Netherlands; ${ }^{2}$ Department of Pulmonary and \\ Critical Care Medicine, Erasmus MC, Rotterdam, The Netherlands and ${ }^{3}$ Department of Molecular Cell \\ Biology, Free University Medical Center, Amsterdam, The Netherlands
}

\begin{abstract}
Dendritic cells (DC) and macrophages $(\mathrm{M} \phi)$ are present in high numbers in the pancreas of the non-obese diabetic (NOD) mouse during the diabetogenic process from very early stages onwards. In this study, we used clodronate-loaded liposomes to mediate the temporary systemic depletion of these phagocytic cells and monocytic precursors in order to modulate the pancreatic inflammation. Two intraperitoneal injections given with a 2-day interval to 8-week-old NOD mice depleted monocytes from the circulation and monocytes, DC and $\mathrm{M} \phi$ from the spleen within the first days after the injections. Monocytes, DC and M $\phi$ reappeared in the circulation and the spleen within one week and had an unchanged phenotype and antigen presenting function. Interestingly, this treatment caused a delayed disappearance (7-21 days postinjection) of DC and M $\phi$ from the endocrine pancreas at a time when monocytes, DC and $M \phi$ had already repopulated the circulation and the spleen. The depletion of $\mathrm{DC}$ and $\mathrm{M} \phi$ from the endocrine pancreas was accompanied by a total disappearance of lymphocytes from the pancreas. DC, $M \phi$ and lymphocytes reappeared in the pancreatic inflammatory infiltrates in treated mice from 28 days postdepletion onwards. Importantly, the treatment significantly postponed the onset of diabetes, leading to a strongly decreased incidence by 35 weeks of age. Taken together, our data show an essential role of phagocytic cells, that is, $\mathrm{DC}$ and $\mathrm{M} \phi$, in the recruitment of lymphocytes to the pancreatic islets in NOD mice.

Laboratory Investigation (2005) 85, 487-501, advance online publication, 17 January 2005; doi:10.1038/labinvest.3700238
\end{abstract}

Keywords: DC; macrophages; NOD; insulitis; diabetes

Type I diabetes is an autoimmune disease in which a self-destructive immune process against the pancreatic $\beta$-cells leads to insulin deficiency. In the non-obese diabetic (NOD) mouse, a widely used animal model for autoimmune diabetes, dendritic cells (DC) and macrophages $(\mathrm{M} \phi)$ have been proposed to be important for the initiation, progression and final destruction of the $\beta$-cells. ${ }^{1}$ Histological studies show slightly raised numbers of DC and $\mathrm{M} \phi$ already in the pancreas of neonatal NOD mice. ${ }^{2} \mathrm{~A}$

Correspondence: Dr T Nikolic, PhD, Department of Pulmonary and Critical Care Medicine, Erasmus MC, PO Box 1738, 3000 DR

Rotterdam, The Netherlands.

E-mail: t.nikolic@erasmusmc.nl

*These two authors contributed equally to this study.

Received 8 September 2004; revised 2 December 2004; accepted 3 December 2004; published online 17 January 2005 further accumulation of $\mathrm{DC}$ and $\mathrm{M} \phi$ around islets at 4-5 weeks of age precedes the peri-insular infiltration of lymphocytes. A relocation of lymphocytes and $\mathrm{M} \phi$ into the islets characterizes the initiation of the final $\beta$-cell destruction. ${ }^{3,4}$ The continuous presence of elevated numbers of DC and M $\phi$ in the NOD pancreas from birth onwards strongly suggests an important role of these cells in the diabetogenic process. Yet, these histological studies are descriptive and therefore inherently inconclusive regarding the functional role of these cells.

Functional approaches have involved the blocking of the intra-islet infiltration of inflammatory cells by an intervention of leukocyte-adhesion to the pancreas endothelium ${ }^{5-7}$ or by inducing a long-term depletion of phagocytic cells. ${ }^{8-10}$ These methods protected mice from diabetes, further strengthening the concept of an essential role of $\mathrm{M} \phi$ and DC in the development of autoimmune diabetes in the NOD 
mouse. However, previous studies mainly focused on the depletion of $\mathrm{M} \phi$ and did not consider the effects of DC depletion. We have previously demonstrated that clodronate-loaded liposomes (lip$\mathrm{CL}_{2} \mathrm{MDP}$ ) not only deplete $\mathrm{M} \phi$ but also DC in liposome-targeted tissues. ${ }^{11}$

We report here an investigation on the intrapancreatic and peripheral changes in the monocyte, DC and $\mathrm{M} \phi$ compartment after a short-term lip-CL ${ }_{2} \mathrm{MDP}$ treatment of NOD mice. We show that two intraperitoneal (i.p.) injections of lip- $\mathrm{CL}_{2} \mathrm{MDP}$ given with a 2-day interval in 8-week-old prediabetic NOD mice significantly delayed diabetes onset for more than 20 weeks in the majority of treated mice. Considering the short-term disappearance of monocytes, $\mathrm{M} \phi$ and DC from the circulation and the spleen, and the rapidly regenerated normal function of the newly recruited spleen DC, the beneficial effects could not be attributed to a modulation of cells from this compartment. However, the same treatment induced a delayed disappearance of DC and $\mathrm{M} \phi$ from the endocrine pancreas. The absence of DC and $\mathrm{M} \phi$ directly influenced the presence of lymphocytes and lymphocytic (peri-)insulitis resolved completely. Our observations point to an essential role of DC and $\mathrm{M} \phi$ in the continued persistence of lymphocytic infiltrates in the pancreas and subsequent $\beta$-cell destruction.

\section{Methods}

\section{Animals}

Female NOD/Ltj and $\mathrm{C} 3 \mathrm{HeB} / \mathrm{FeJ}$ mice were bred at the animal facility of the ErasmusMC, Rotterdam, The Netherlands. C57BL/6j female mice were obtained from Harlan (Horst, The Netherlands). All strains were kept under specific pathogen-free conditions and fed ad libitum. By 30 weeks of age, the incidence of diabetes in our NOD colony is $90 \%$ for females and $60 \%$ for males. For all experiments, mice were killed at postnatal ages of $7-12$ or at 35 weeks of age. Glycosuria was tested with the Gluketur test (Roche Diagnostics GmbH, Mannheim, Germany). A minimum of 3 animals per age/strain/ time point was used for the kinetics studies. Animal handling followed the ethical rules of the European Union and was approved by the Erasmus University Animal Welfare Committee.

\section{Liposome Preparation and In Vivo Application}

Multilamellar liposomes containing clodronate (dichloromethylene bisphosphonate, a gift from Roche Diagnostics $\mathrm{GmbH}$ ) (lip-CL $\mathrm{CL}_{2} \mathrm{MDP}$ ) in the aqueous phase were prepared as described previously. ${ }^{12,13}$ Liposomes consisted of phosphatidyl choline and cholesterol in 6:1 molar ratio. After washing, the liposomes were resuspended in phosphate-buffered saline (PBS). A volume of $0.2 \mathrm{ml}$, containing about $2 \mathrm{mg}$ of liposome-entrapped clodronate, was injected twice i.p. with a 2-day interval between two consecutive injections into 8-week-old mice (in a stage of well-advanced peri-insulitis). This approach was chosen in order to obtain a complete depletion of phagocytic cells in the spleen. Mice were killed (by $\mathrm{CO}_{2}$ exposure) at various time points after the second injection (days 2, 4, 7, 14, 21,28 ) and indicated organs were removed for analysis.

\section{Diabetes Incidence after Treatment with Lip-CL ${ }_{2} \mathrm{MDP}$}

A group of lip- $\mathrm{CL}_{2} \mathrm{MDP}$-treated or untreated mice were followed until 35 weeks of age and glycosuria $(>2+)$ was measured weekly. Mice from both groups that were found diabetic during the observation period were registered and excluded from the further follow-up. Mice without clinical signs of diabetes at 35 weeks of age (eight mice from the treated group and none from the untreated group) were killed and the pancreases were removed and embedded in Tissue-Tek (Miles, Elkart, IN, USA) and frozen in liquid nitrogen. Cryostat sections ( $5 \mu \mathrm{m}$ thick) were cut at 100 or $200 \mu \mathrm{m}$ intervals. The pancreas was analyzed for the presence of insulitis by immunohistochemistry (see later).

Insulitis score in the 35-week-old diabetes-free mice was determined by analyzing the composition of islets with respect to the presence of insulin- and glucagon-positive cells, $\mathrm{T}$ cells, DC or $\mathrm{M} \phi$ in histological examination of sequential sections stained for each cell type, according to the staging established previously. ${ }^{3}$ A numerical score was ascribed to the four stages as follows: stage 0 (unaffected islets)—score 0, stage I + II (early parainsular accumulation of $\mathrm{DC}$ and $\mathrm{M} \phi$, no $\mathrm{T}$ cells present, insulin ${ }^{+}$)—score 1, stage III + IV (para- and peri-insular accumulation of DC, $\mathrm{M} \phi$ and T cells, insulin $^{+}$)—score 2 , stage $\mathrm{V}$ (infiltration of $\mathrm{T}$ cells into islets, insulin ${ }^{+}$)—score 3 , stage VI (end stage, insulin $^{-}$)-score 4 . In the latter case, labeling with glucagon identified islet remnants. A score was assigned to each detected islet and an average islet score/mouse was calculated. The number of islets per mouse varied between 20 and 150 (and more) and was clearly correlated with the stage of the destructive process in NOD mice. In C57BL mice, we analyzed more than 200 islets.

\section{Immunohistochemistry}

Three separate series of five or six pancreas sections, cut at different levels, were analyzed to obtain the representation of a total pancreas. Sections were fixed for $10 \mathrm{~min}$ in acetone containing $0.03 \%$ hydroxyperoxide to block endogenous peroxidases. PBS with $0.05 \%$ Tween-20 was used for the washing steps. Unconjugated primary antibodies specific for 
insulin, glucagon, T cells (CD3), DC (CD11c) or subsets of $\mathrm{M} \phi$ (ER-MP23 or $\mathrm{BM}^{14}$ ) were subsequently detected with appropriate peroxidasecoupled (DAKO, Glosstrup, Denmark) secondary antibodies in the presence of $1.5 \%$ normal mouse serum. The 3-amino-9-ethylcarbazole substrate (Sigma Co., St Quentin Fallavier, France) dissolved in $50 \mathrm{mM}$ sodium acetate/0.02\% hydroxyperoxide was used to detect peroxidase activity. The resulting labeling was examined by light microscopy.

\section{Preparation of Single-Cell Suspension of Circulating Leukocytes and Spleen}

Blood was obtained by heart puncture after exposing the organ, and collected in heparin-coated tubes or in syringes containing $1 \mathrm{ml}$ PBS with $8 \mathrm{mM}$ EDTA. Erythrocytes were eliminated using lysing solution (BD Biosciences, San Diego, CA, USA) and leukocytes were washed twice by centrifugation at $400 \mathrm{~g}$ in PBS supplemented with $0.5 \%$ BSA and $20 \mathrm{nM}$ $\mathrm{NaN}_{3}$ (further referred to as the FACS buffer).

The spleen was cut into two parts. The larger part was used for histological analysis. The smaller part of the spleen was cut into small pieces and incubated for $1 \mathrm{~h}$ at $37^{\circ} \mathrm{C}$ with collagenase-D (Roche Diagnostics $\mathrm{GmbH}$; $0.27 \mathrm{U} / \mathrm{mg}$ ) at a final concentration of $1 \mathrm{mg} / \mathrm{ml}$ in RPMI-1640 medium supplemented with $60 \mu \mathrm{g} / \mathrm{ml}$ penicillin and $100 \mu \mathrm{g} / \mathrm{ml}$ streptomycin. The resulting digested tissue suspension was pushed through a $100 \mu \mathrm{m}$ cell strainer using a rubber-end of a $5 \mathrm{ml}$ syringe plunger and centrifuged. Subsequently, the cell suspension was washed with RPMI-1640 medium supplemented with antibiotics and 10\% fetal calf serum (FCS).

\section{Spleen DC Isolation by MACS Procedure}

DC were sorted from the spleen cell suspension by magnetic enrichment using auto-MACS. Cells were centrifuged, resuspended to obtain a concentration of $1 \times 10^{8}$ cells in $400 \mu \mathrm{l}$ MACS buffer (PBS supplemented with $1 \%$ FCS and $2 \mathrm{mM}$ EDTA) and incubated with $100 \mu \mathrm{l}$ CD11c microbeads (Miltenyi Biotec GmbH, Germany) for $30 \mathrm{~min}$ on ice. Subsequently, cells were washed twice and then resuspended in MACS buffer to obtain a concentration of $1 \times 10^{8}$ cells $/ \mathrm{ml}$. The program for high purity of cells with low frequency was used on the autoMACS machine (Miltenyi Biotec $\mathrm{GmbH}$ ) and a positive fraction was collected. In all experiments, the purity was higher than $95 \%$ as determined by subsequent flowcytometric analysis.

\section{Phenotypic Analysis}

The list of antibodies used in this study is given in the Table 1 . Aliquots of $2 \times 10^{6}$ cells were incubated with the prepared mix of monoclonal antibodies. Each incubation step was performed at room temperature for $10 \mathrm{~min}$. All biotinylated antibodies were detected by streptavidin-APC (BD Biosciences). Anti-CD71 was detected by R-PE labeled goat-anti-rat IgG (mouse-absorbed; G $\alpha$ Ra-PE) purchased from Caltag Laboratories, San Francisco, CA, USA.

\section{Mixed Leukocyte Reaction}

The capacity of the sorted spleen DC to activate allogeneic $\mathrm{T}$ cells was measured as previously

Table 1 Monoclonal antibodies used in this study

\begin{tabular}{|c|c|c|c|}
\hline Marker & Monoclonal antibody & Conjugate & Origin \\
\hline Ly-6G & $1 \mathrm{~A} 8$ & $\mathrm{PE}$ & BD Biosciences $^{\mathrm{a}}$ \\
\hline Ly-6C & ER-MP20 & FITC & Own laboratory \\
\hline CD11b/Mac-1 & $\mathrm{M} 1 / 70$ & PerCP & BD Biosciences \\
\hline CD11c & N418; HL3 & $\varnothing^{\mathrm{b}} ;$ FITC, PE & Own laboratory; BD Biosciences \\
\hline CD43 & S7 & FITC, PE & BD Biosciences \\
\hline $\operatorname{CD} 8 \alpha$ & $53-6.7$ & FITC, APC & BD Biosciences \\
\hline $\mathrm{F} 4 / 80$ & $\mathrm{~F} 4 / 80$ & FITC & Caltag Lab, SanFrancisco, CA, USA \\
\hline CD31 & ER-MP12 & bio & Own laboratory \\
\hline CD45RB & $16 \mathrm{~A}$ & FITC & BD Biosciences \\
\hline MHC class II $\left(\mathrm{I}-\mathrm{A}^{\mathrm{b}}\right)$ & ER-TR3 & bio & BMA Biomedicals AG, Switzerland \\
\hline MHC class II (I-A $\left.{ }^{g 7}\right)$ & 10.2.16 & bio & Own laboratory \\
\hline CD80 & 16-10A1 & $\mathrm{PE}$ & BD Biosciences \\
\hline CD86 & GL1 & FITC & BD Biosciences \\
\hline CD4 & RM4-5 & APC & BD Biosciences \\
\hline Insulin & & $\varnothing$ & DAKO, Carpinteria, USA \\
\hline Glucagon & & $\varnothing$ & DAKO, Carpinteria, USA \\
\hline CD3 & KT3 & $\varnothing$ & Own laboratory \\
\hline ER-MP23 & ER-MP23 & $\varnothing$ & Own laboratory \\
\hline BM8 & BM8 & $\varnothing$ & BMA Biomedicals AG, Switzerland \\
\hline CD71 & ER-MP21 & $\varnothing$ & Own laboratory \\
\hline
\end{tabular}

${ }^{\mathrm{a}}$ San Diego, CA, USA.

${ }^{\mathrm{b}}$ Unconjugated. 
described. ${ }^{15}$ Briefly, responder T cells, isolated from the lymph nodes of $\mathrm{C} 3 \mathrm{H}$ mice, and stimulator cells (DC) were resuspended in RPMI-1640 (with HEPES), $10 \%$ FCS (heat inactivated; $0.2 \mu \mathrm{m}$ filtered), $60 \mu \mathrm{g} / \mathrm{ml}$ penicillin, $100 \mu \mathrm{g} / \mathrm{ml}$ streptomycin, $20 \mathrm{mg} / \mathrm{l}$ sodium pyruvate and $50 \mu \mathrm{M}$ 2-ME (further referred to as MLR medium). $T$ cells were resuspended at a concentration of $10^{6} / \mathrm{ml}$. The concentration of stimulator cells varied depending on the desired stimulator:responder cell ratio. The cells $(100 \mu \mathrm{l}$ of each cell suspension) were incubated in roundbottom 96-well plates for 4 days at $37^{\circ} \mathrm{C}$ in $7 \% \mathrm{CO}_{2}$. Stimulator and responder cells, incubated separately in MLR medium, were used as negative controls. Mitogenic stimulation of T cells by concanavalin A (final concentration $1.25 \mu \mathrm{g} / \mathrm{ml}$ ) (Sigma Chemical Co., St Louis, MO, USA) was used as a positive control for cell proliferation.

After 4 days of coculture, cells were harvested and analyzed by flow cytometry. Triple labeling of cells with antibodies against CD4, CD8 and CD71 (antitransferrin receptor) was performed and $1.5 \times 10^{4}$ events were acquired within the live cell gate. Data analysis was performed using Cell Quest Pro analysis software. The percentage of CD71-positive $\mathrm{T}$ cells, as a measure of proliferating cells, was determined within the $\mathrm{CD} 4^{+}$and $\mathrm{CD}^{+}$population.

\section{Results}

Treatment of 8-Week-Old Prediabetic NOD Mice with lip-CL ${ }_{2}$ MDP Significantly Delays the Onset of Diabetes

To investigate the modulating effects of temporary phagocyte depletion on pancreatic inflammation and diabetogenesis, we treated NOD mice with two i.p. injections of lip- $\mathrm{CL}_{2} \mathrm{MDP}$. This treatment caused a significantly delayed incidence of diabetes when compared to the corresponding untreated group $(P<0.01)$ (Figure 1a). At the end point of our study (35 weeks of age), the majority of treated NOD mice $(73 \%)$ were still normoglycemic while the only mouse $(12.5 \%)$ that survived to this age within the untreated group was diabetic.

Immunohistological examination of the pancreases of remaining nondiabetic treated mice (35-week-old) showed that none of the mice had been permanently protected from the destructive insulitis. Leukocyte accumulations in the endocrine pancreas were present in all mice at 35 weeks of age. The infiltrates comprised DC, $\mathrm{M} \phi$ and T cells, and the composition varied per individual islet, depending on the stage of the destructive process, as has been described before for nontreated mice. ${ }^{3}$ In addition, average insulitis score in treated NOD mice at 35 weeks varied significantly among different mice (Figure 1b). Mice were segregated into two subgroups: (I) majority of them (five of eight) with the insulitis score around 4 (like that of diabetic mouse) and (II) three mice with the insulitis
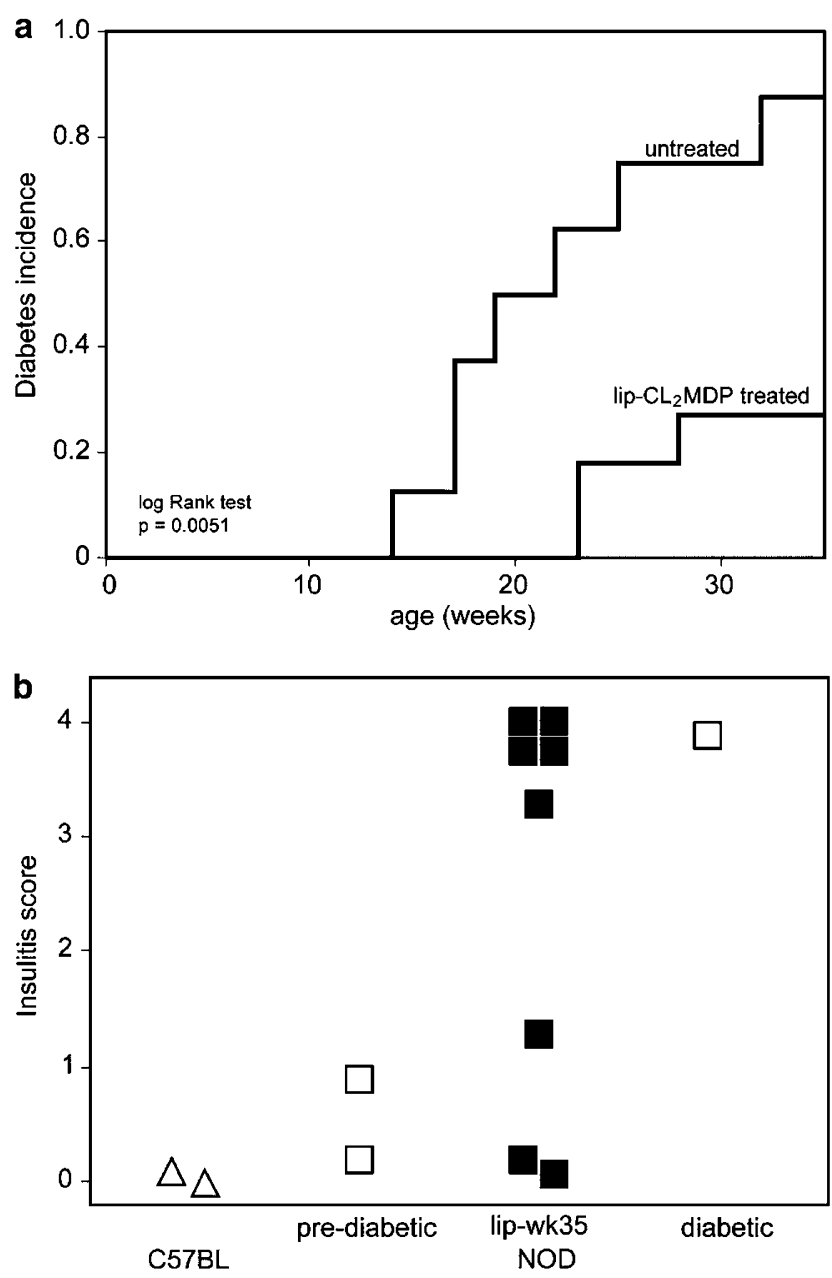

Figure 1 A short-term treatment of NOD mice with lip- $\mathrm{CL}_{2} \mathrm{MDP}$ induced a significant delay of diabetes onset, resulting in strongly reduced incidence at 35 weeks of age. (a) Kaplan-Meier analysis of the diabetes incidence in treated and untreated NOD mice. The log rank statistical test was performed to compare the KaplanMeier curves of the diabetes incidence of the untreated and lip$\mathrm{CL}_{2} \mathrm{MDP}$-treated mice $(P<0.01)$. (b) Calculation of the insulitis score of individual diabetes-free lip- $\mathrm{CL}_{2} \mathrm{MDP}$-treated NOD mice at 35 weeks of age (filled squares) shows that majority of these mice had an advanced destructive insulitis, similar to that of an untreated diabetic mouse (empty square). However, three diabetes-free lip-CL ${ }_{2}$ MDP-treated NOD mice had an insulitis score similar to that of prediabetic (11-week-old) untreated NOD mice (empty square). Scores of control untreated C57BL mice (empty triangles) were also calculated. A detailed description of scoring is given in the Methods section.

score of less than 2 (similar to that of nontreated prediabetic 11-week-old NOD mice) (Figure 1b).

Hence, a two-fold injection of lip- $\mathrm{CL}_{2} \mathrm{MDP}$ strongly delayed the diabetes onset in majority of treated mice for 18-24 weeks, yet did not prevent the destructive inflammation in the pancreas of NOD mice. Nevertheless, the reduced progression of the established pathogenic process in treated NOD mice suggested the important modulation effect of short-term treatment with lip- $\mathrm{CL}_{2} \mathrm{MDP}$, which we further investigated. 
Monocytes, DC and M $\phi$ Return Rapidly to the Spleen of NOD Mice after the Depletion

Previous studies have revealed negligible effects of the lip- $\mathrm{CL}_{2} \mathrm{MDP}$ treatment on the lymphocyte pool. ${ }^{9,10}$ A long-term treatment with lip- $\mathrm{CL}_{2} \mathrm{MDP}$ did not modify the pancreatic islet-directed destructive capacity of the T-cell pool in the NOD mouse. However, the short-term effects of the lip- $\mathrm{CL}_{2} \mathrm{MDP}$ treatment on the myeloid cells have not been investigated extensively. Therefore, we followed the disappearance of monocytes, DC and $\mathrm{M} \phi$ and the kinetics of their repopulation in the circulation and the spleen in the NOD mice and the identically treated control C57BL.

Blood monocytes were quantified using a recently established analysis ${ }^{16}$ in which monocytes are gated as SSC ${ }^{\text {lo }} \mathrm{CD} 11 \mathrm{~b}^{\text {hi }}$ cells. Blood monocytes consist of an immature pool ( $\left.\mathrm{Ly}-6 \mathrm{C}^{\mathrm{hi}}\right)$, readily recruited into inflammations, and mature monocytes $\left(\mathrm{Ly}-6 \mathrm{C}^{\mathrm{lo}}\right)$, a resident DC and $\mathrm{M} \phi$ precursor pool. ${ }^{17}$ For the quantification of $\mathrm{DC}$ and $\mathrm{M} \phi$ in the spleen by a flowcytometric analysis, monoclonal antibodies against CD11c, $\mathrm{CD} 8 \alpha, \mathrm{CD} 11 \mathrm{~b}$ and $\mathrm{F} 4 / 80$ were applied simultaneously. This enabled definition of four distinct cell populations (Figure 2a). CD11c ${ }^{+}$ cells (gate: R1) were subdivided into $\mathrm{CD} 11 \mathrm{c}^{+} \mathrm{CD} 11 \mathrm{~b}^{\mathrm{hi}}$ $\mathrm{CD}^{-}{ }^{-}$(myeloid DC) and CD11c ${ }^{+} \mathrm{CD} 11 \mathrm{~b}^{\text {lo }} \mathrm{CD}^{+}$cells $\left(\mathrm{CD}^{+} \mathrm{DC}\right)$. A third population, $\mathrm{CD} 11 \mathrm{c}^{-} \mathrm{CD} 11 \mathrm{~b}^{\mathrm{hi}} \mathrm{F} 4 /$ $80^{+}$(gate: R2), represent the red pulp $\mathrm{M} \phi$ as verified by immunohistochemistry. The F4/80-negative fraction in the R2 gate were granulocytes. Finally, the CD11 $\mathrm{c}^{\text {lo }} \mathrm{CD} 11 \mathrm{~b}^{\mathrm{hi}}$ cells (gate: R3) formed a fourth population; these cells were $\mathrm{F} 4 / 80^{\mathrm{lo}}$, $\mathrm{Ly}-6 \mathrm{C}^{\mathrm{lo} / \mathrm{med}}$, $\mathrm{CD} 43^{+}, \mathrm{CD} 31^{+}$and correspond to the mature blood monocytes as we have recently defined. ${ }^{16}$

Treatment with lip- $\mathrm{CL}_{2} \mathrm{MDP}$ (i.v.) causes the virtually complete depletion of circulating monocytes during the first hours, followed by a rapid return. ${ }^{16}$ Starting from the day 2 after the i.p. treatment, the pool of Ly-6C $\mathrm{C}^{\text {hi }}$ monocytes did not change. In contrast, the Ly-6C $\mathrm{C}^{\text {lo }}$ monocyte population was almost completely depleted at day 2 and significantly reduced until the end of the observation period (day 28) (Table 2). Similar kinetics were found for the C57BL control mice (not shown).

Mature monocytes, DC and $\mathrm{M} \phi$ in the spleen were clearly depleted at day 2 after the last injection of lip-CL ${ }_{2}$ MDP (Figure 2b). All four investigated cell groups were present in the spleen of the treated mice, starting from day 4 in both mouse strains. Myeloid DC reached steady-state levels in the second week post-treatment, while $\mathrm{CD}^{+}$DC needed more than 2 weeks to normalize (Figure 2b). Similar kinetics was found for the NOD and C57BL mice. Red pulp $\mathrm{M} \phi$ were restored almost instantly: despite a short initial drop, the rate of NOD red pulp $\mathrm{M} \phi$ remained stable at the steadystate level with even a slight increase at day 11 . However, in C57BL mice, the frequency of red pulp $\mathrm{M} \phi$ remained significantly higher till the end of the observation period. Splenic mature monocytes were also depleted at day 2, but returned to normal levels shortly thereafter and remained stable from day 4 onwards in both mouse strains (Figure 2b).

\section{Observations in Flowcytometric Analysis are Confirmed by the Immunohistological Analysis}

Immunohistological analysis of CD11C ${ }^{+}$(myeloid $\mathrm{DC}$ and $\mathrm{CD}^{+} \mathrm{DC}$ ) and $\mathrm{F} 4 / 80^{+}$cells (mature monocytes and $\mathrm{M} \phi$ ) in the spleen indicated the same kinetics as the flowcytometric analysis. As shown in Figure 3, treatment with lip- $\mathrm{CL}_{2} \mathrm{MDP}$ induced a complete depletion of both $\mathrm{M} \phi$ and DC from the spleen of NOD mice: 2 days after the second injection, the red pulp was devoid of viable F4/80- or CD11c-positive cells (Figure 3c and d). The remaining F4/80- and CD11c-positive labeling in the white pulp at day 2 resembled nonviable pycnotic cells that lacked a typical membrane staining as present in the spleen of nontreated control mice (Figure 3a and b). These were presumably the remnants of $\mathrm{M} \phi$ and DC that died by apoptosis induced by lip- $\mathrm{CL}_{2} \mathrm{MDP}$, as reported previously. ${ }^{18}$

$\mathrm{F} 4 / 80^{+}$cells started to return to the red pulp from day 4 postinjection onwards (Figure $3 \mathrm{f}$ ) and at day 7 (Figure $3 \mathrm{~h}$ ) the number and the distribution of the F4/80-positive population were comparable to nondepleted control mice. The repopulation of the spleen by CD11c ${ }^{+}$cells also started at day 4 (Figure $3 \mathrm{e}$ ) and at day $14 \mathrm{CD} 11 \mathrm{c}^{+}$cells in NOD mice had regained their normal staining pattern as compared to the untreated controls (Figure 3g). In addition, other $\mathrm{M} \phi$ populations like metalophillic (MOMA$1^{+}$) and marginal zone (ER-TR9 ${ }^{+}$) M $\phi$ were depleted in NOD mice by lip-CL ${ }_{2}$ MDP in the same fashion as has been reported for other mouse strains. ${ }^{19}$ These cells, however, only reappeared several weeks after depletion (data not shown).

Taken together, the kinetics of depletion and repopulation by different populations of splenic DC and $\mathrm{M} \phi$ in NOD mice is fully comparable with the repopulation in C57BL mice.

\section{A Normal Phenotype and Function of Repopulated Spleen DC in NOD Mice after the Depletion}

Despite the rapid return, the function of the returning phagocytes might be modulated by the treatment with lip-CL ${ }_{2}$ MDP leading to the modified contribution to diabetogenesis. Therefore, we compared the phenotype and the function of spleen CD $11 \mathrm{c}^{+}$cells, isolated by an autoMACS procedure, from both treated (day 7 postinjection) and nontreated NOD and C57BL mice. Although we utilized a high-purity separation program, both $\mathrm{CD} 11 \mathrm{c}^{\mathrm{hi}}$ and CD11 $\mathrm{C}^{\text {lo }}$ cells were isolated, based on the phenotypic analysis (Figure 4a). We found no difference in the cell yield between NOD and C57BL mice from both 
a

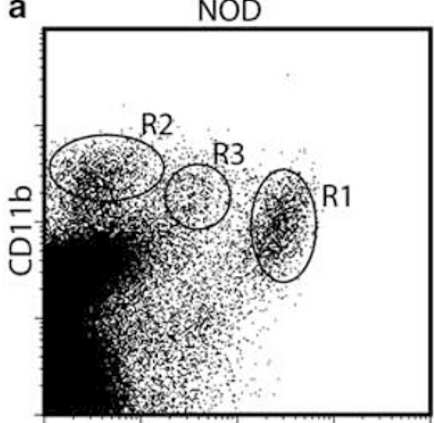

CD11C

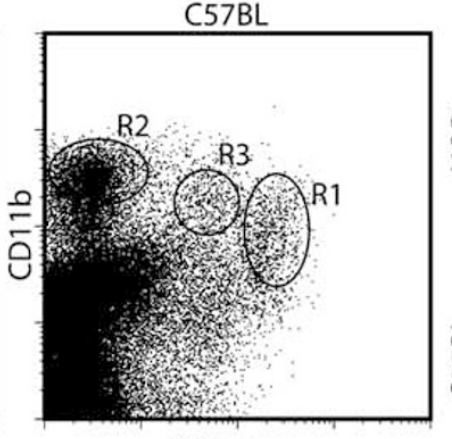

CD11C gate: R1

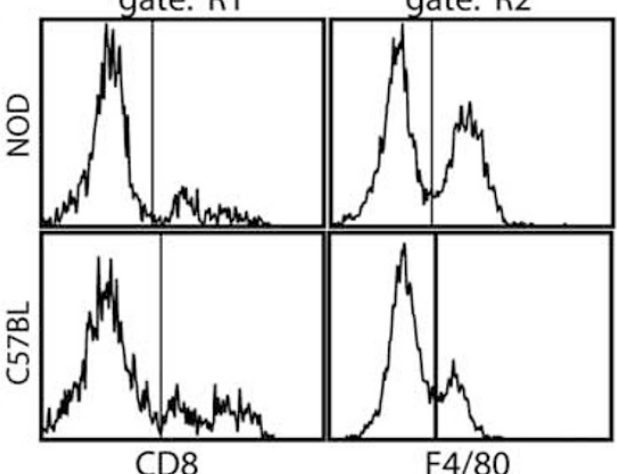

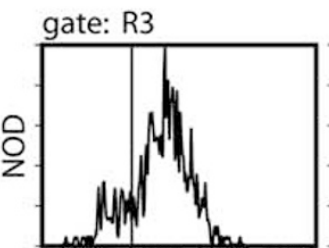
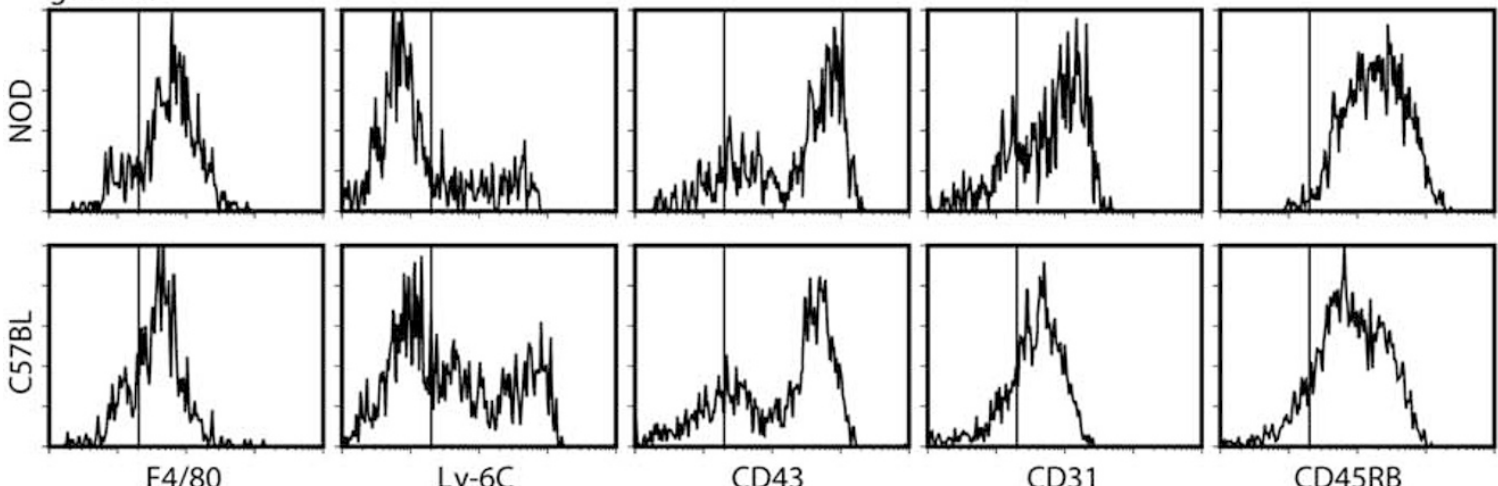

CD43

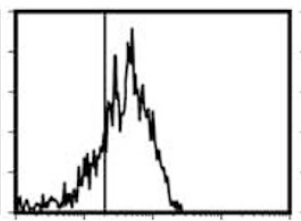

CD31

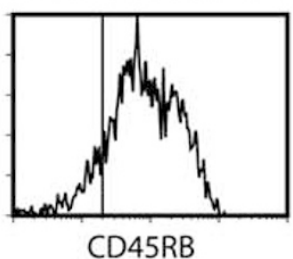

b myeloid DC
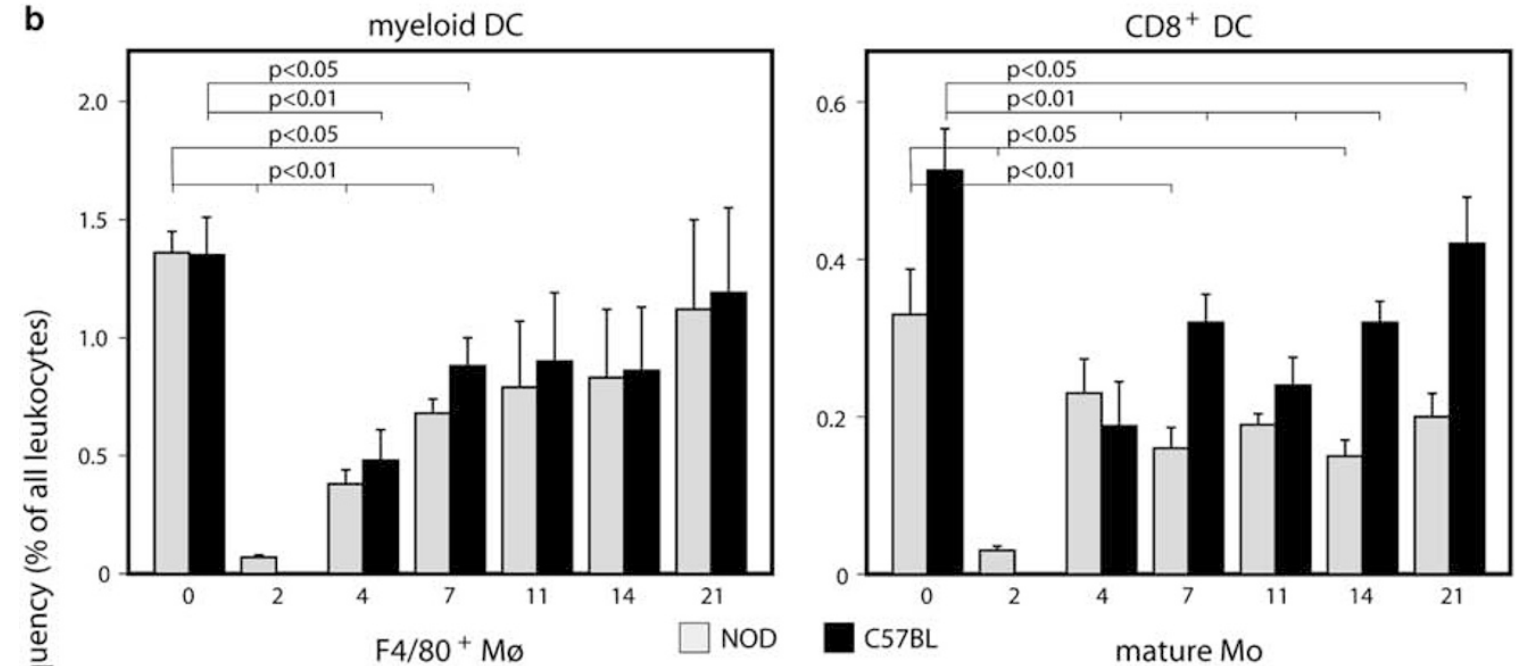

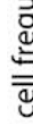

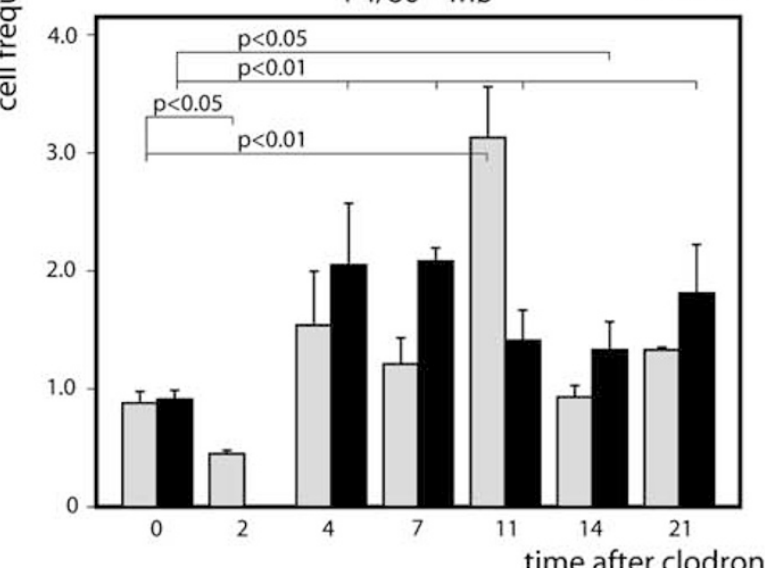

$\square$ C57BL mature Mo

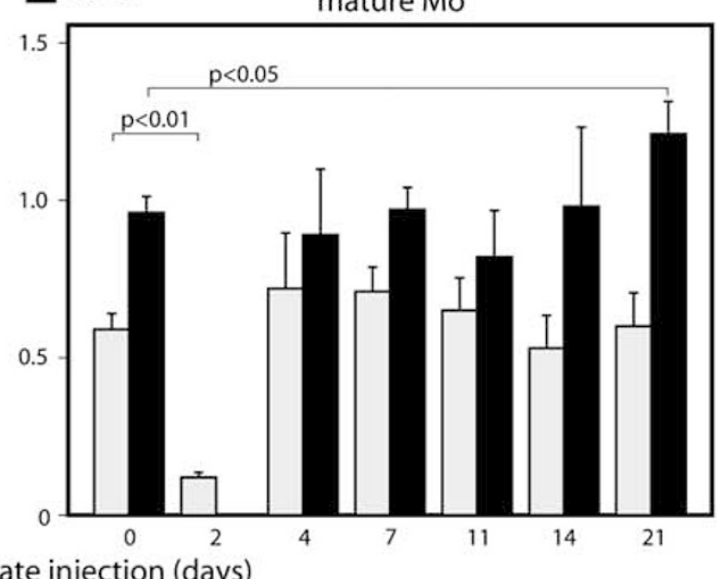


Table 2 Kinetics of the blood monocytes repopulation in NOD mice after lip- $\mathrm{CL}_{2} \mathrm{MDP}$ treatment

\begin{tabular}{|c|c|c|c|}
\hline $\begin{array}{l}\text { Time point } \\
\text { (days) }\end{array}$ & All monocytes & $\begin{array}{c}\text { Inflammatory } \\
\text { Ly-6C } \\
\text { monocytes }\end{array}$ & $\begin{array}{c}\text { Mature Ly-6C }{ }^{l o} \\
\text { monocytes }\end{array}$ \\
\hline 0 & $13.03 \pm 1.36^{\mathrm{a}}$ & $4.47 \pm 0.33$ & $8.56 \pm 1.05$ \\
\hline 2 & $5.83 \pm 0.57^{*}$ & $5.28 \pm 0.61$ & $0.55 \pm 1.07^{* *}$ \\
\hline 4 & $9.74 \pm 0.81$ & $5.87 \pm 1.72$ & $3.87 \pm 0.04 *$ \\
\hline 7 & $10.87 \pm 1.49$ & $5.97 \pm 1.04$ & $4.90 \pm 0.74$ * \\
\hline 14 & $14.04 \pm 3.51$ & $9.73 \pm 2.68$ & $4.31 \pm 0.93$ * \\
\hline 28 & $12.26 \pm 1.59$ & $7.37 \pm 1.57$ & $4.89 \pm 0.83^{*}$ \\
\hline
\end{tabular}

${ }^{\mathrm{a}}$ Data represent mean \pm s.e.m.

${ }^{*} P<0.05 ;{ }^{* *} P<0.01$ vs 0 time point.

untreated and treated mice. Also, the isolated CD11 ${ }^{+}$cells from treated mice displayed the same expression of MHC class II and of the costimulatory molecules CD80 and CD86 in comparison to such cells isolated from nontreated mice (Figure 4a). In addition, the T-cell-stimulating capacity of the isolated DC cocultured with allogeneic T cells was similar before and after the treatment, in both mouse strains (Figure 4b). Similar proportions of allogeneic $\mathrm{CD}^{+}$or $\mathrm{CD}^{+} \mathrm{T}$ cells had upregulated CD71 (transferrin-receptor), irrespective of the fact that the cells isolated from treated mice had a higher proportion of mature monocytes than before treatment.

\section{Lip- $\mathrm{CL}_{2} \mathrm{MDP}$ Treatment Leads to a Late Disappearance of DC and $M \phi$ from the NOD Pancreas}

To examine the effect of lip- $\mathrm{CL}_{2} \mathrm{MDP}$ treatment on the target organ inflammation, pancreases were removed before and after the injections (at days 0, $2,4,7,14$ and 28 post-treatment), and the presence of the different cell populations was examined by immunohistochemical staining.

Untreated (8-week-old) NOD mice had a considerable lymphocytic peri- and intra-islet infiltration. $\mathrm{BM}^{+}$and ER-MP23 ${ }^{+} \mathrm{M} \phi$ (Figure 5a and b) were found scattered throughout the pancreas and most likely represent resident $\mathrm{M} \phi$. Unlike $\mathrm{M} \phi$, DC $\left(\mathrm{CD} 11 \mathrm{c}^{+}\right)$were localized only in close proximity to the islets and not in the intra- and inter-lobular septa of the exocrine pancreas (Figure 7a).
The treatment with lip- $\mathrm{CL}_{2} \mathrm{MDP}$ had no immediate effect on pancreas $\mathrm{M} \phi$ and DC, unlike hitherto observed in the spleen and the circulation. However, starting from day 4 after the treatment, we observed reduced numbers of $\mathrm{BM}^{+}$and ER-MP23 ${ }^{+} \mathrm{M} \phi$ in both exocrine and endocrine pancreas (not shown). The decline in the $\mathrm{M} \phi$ number further continued and many islets were clear from $\mathrm{M} \phi$ (Figure 5c and d). Quantification of $\mathrm{M} \phi$-containing islet-inflammations at day 7 post-treatment showed that about $95 \%$ of islets were free of $\mathrm{M} \phi$ (Figure 6a), and the frequency of islets that contained $\mathrm{M} \phi$ was almost as low as in C57BL mice of the same age. Additionally, at day 14 after injection, many islets and exocrine lobes were devoid of $\mathrm{M} \phi$ (Figures 5e, $\mathrm{f}$ and 6a). The distribution of the few remaining $\mathrm{M} \phi$ had also drastically changed as they were found only in confined areas such as the interlobular connective tissue, but not associated with endocrine or exocrine cells. At 28 days after treatment, $\mathrm{M} \phi$ had reappeared again at the islet periphery (Figure $5 \mathrm{~g}$ and $\mathrm{h})$.

Similar to $\mathrm{M} \phi$, the number of pancreatic DC declined from day 4 after treatment onwards (Figure 6b). At days 7 and 14, the short-term injection of lip$\mathrm{CL}_{2} \mathrm{MDP}$ had almost completely depleted DC from NOD pancreases. When quantified, the number of DC-free islets was similar to the number of $\mathrm{M} \phi$-free islets (Figure 6b). Also like $\mathrm{M} \phi$, DC were again present in islets at day 28 after lip- $\mathrm{CL}_{2} \mathrm{MDP}$ injection (Figure 7g).

\section{The Loss of M $\phi$ and DC from NOD Pancreas Leads to a Prolonged Disappearance of Lymphocytes}

In parallel with the loss of $\mathrm{M} \phi$ and $\mathrm{DC}$, we observed a disappearance of lymphocytes from the pancreases of treated mice (Figure 6b) whereas the phenotypic analysis of the spleen did not reveal changes in the lymphocyte frequency (not shown). The decline in DC and $\mathrm{M} \phi$ numbers at day 4 already correlated to the loss of lymphocytes from the pancreatic infiltrates (not shown). This phenomenon was more prominent at days 7 and 14 after treatment and observed in parallel with the absence of DC (Figure $7 \mathrm{~d}$ and f). At day-28, when a substantial number of $\mathrm{DC}$ and $\mathrm{M} \phi$ had returned to the pancreas, T cells also reappeared (Figure $7 \mathrm{~h}$ ). B cells demonstrated a similar kinetics as $\mathrm{T}$ cells. At day 4 , the numbers

Figure 2 Normal maturation kinetics of the NOD DC and $\mathrm{M} \phi$ compartment after lip- $\mathrm{CL}_{2} \mathrm{MDP}$ in the spleen. (a) Phenotypic definition of the spleen DC and $\mathrm{M} \phi$ populations according to CD11b and CD11c expression. Histograms represent the expression profile for a given marker, of cells that belong to the indicated gate. CD11 ${ }^{\text {hi }}$ cells (gate: R1) can be divided into CD8 ${ }^{+}$DC and myeloid DC (CD8 ${ }^{-}$). The $\mathrm{F} 4 / 80^{+}$population within $\mathrm{CD} 11 \mathrm{c}^{-} \mathrm{CD} 11 \mathrm{~b}^{\mathrm{hi}}$ cells (gate: R2) represent the red pulp $\mathrm{M} \phi$ (verified by immunohistochemistry). The $\mathrm{CD} 11 \mathrm{C}^{\mathrm{lo}} \mathrm{CD} 11 \mathrm{~b}^{\mathrm{hi}}$ (gate: R3) cells correspond to mature blood monocytes and are F4/80 $0^{\mathrm{lo}}$, Ly-6C $\mathrm{Co}^{\mathrm{lo} / \mathrm{med}}, \mathrm{CD} 3^{+}, \mathrm{CD} 1^{+}$and $\mathrm{CD} 45 \mathrm{RB}{ }^{+}$. The vertical line represents the negative control limit. (b) Time course of the depletion and repopulation of the myeloid cells in the spleen as defined by phenotype in (a). Each bar represents an average value of a minimum of three mice per mouse strain per time point $P$-values indicated in graphs represent the statistical significance (Student's $t$-test) of the indicated time point $v s$ the point 0 for a given mouse strain. 

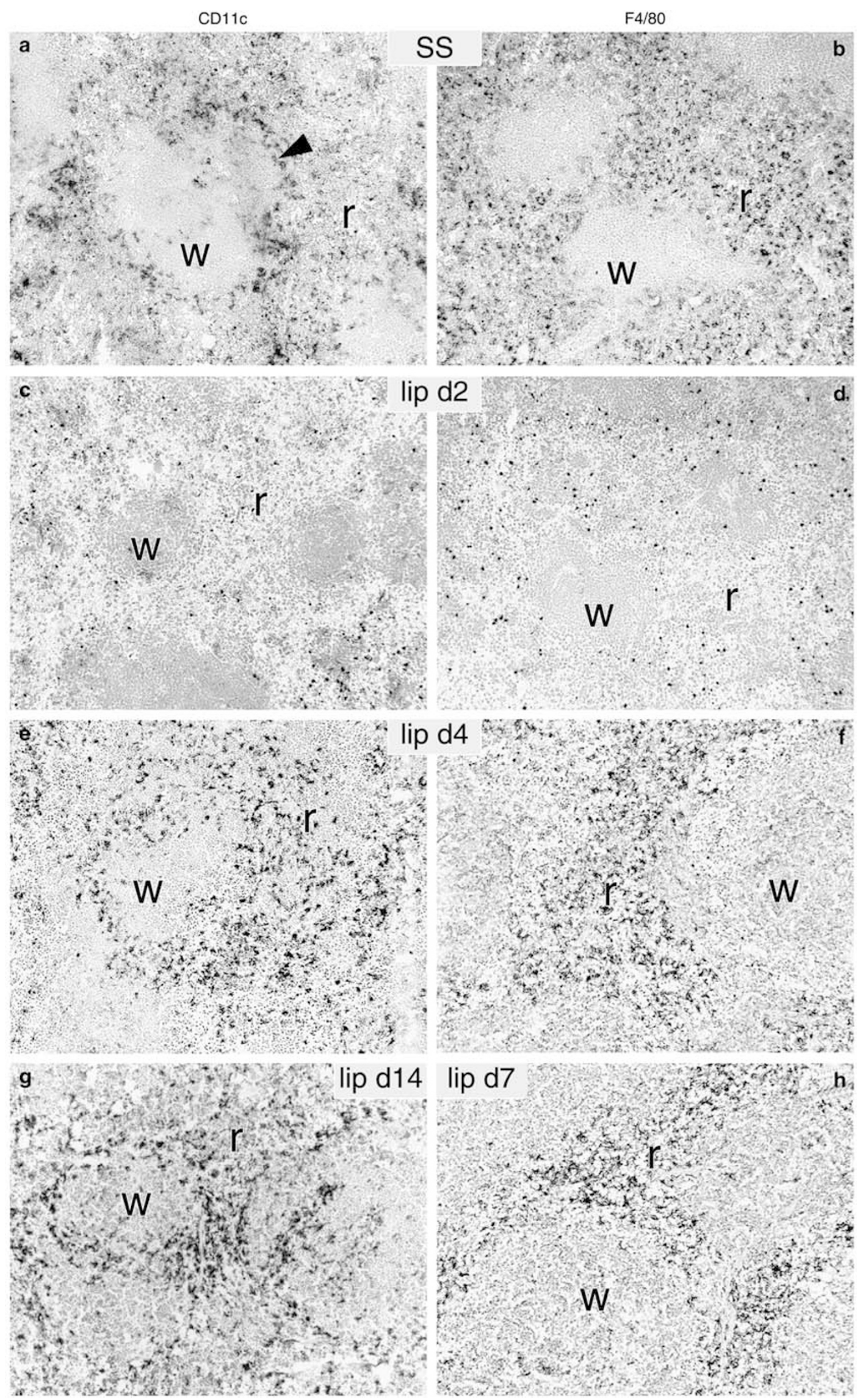


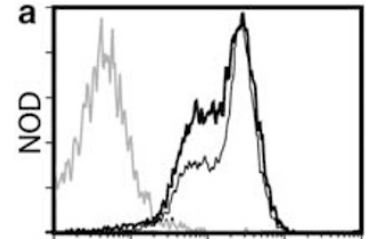

CD11c

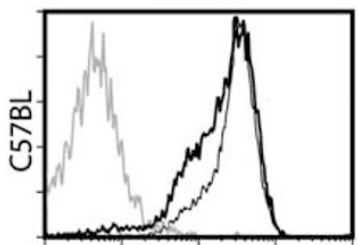

CD11c

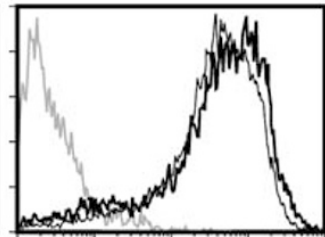

MHC class II

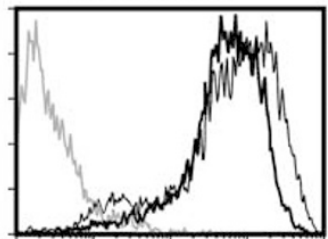

MHC class II

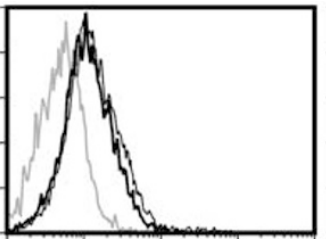

CD86

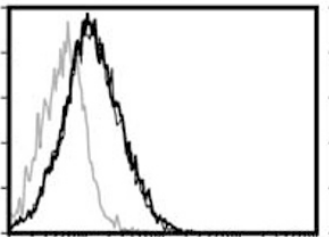

CD86

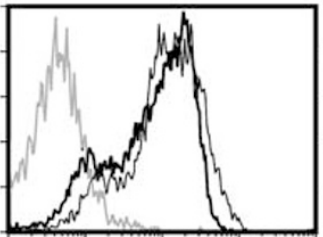

CD80

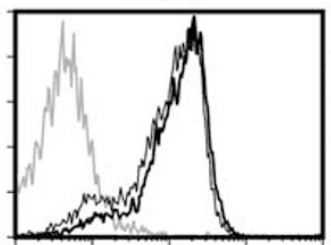

CD80

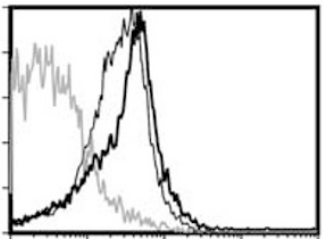

$\mathrm{F} 4 / 80$

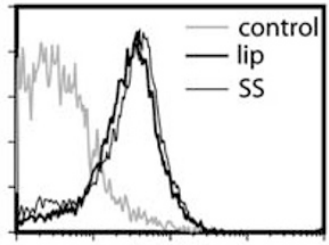

F4/80
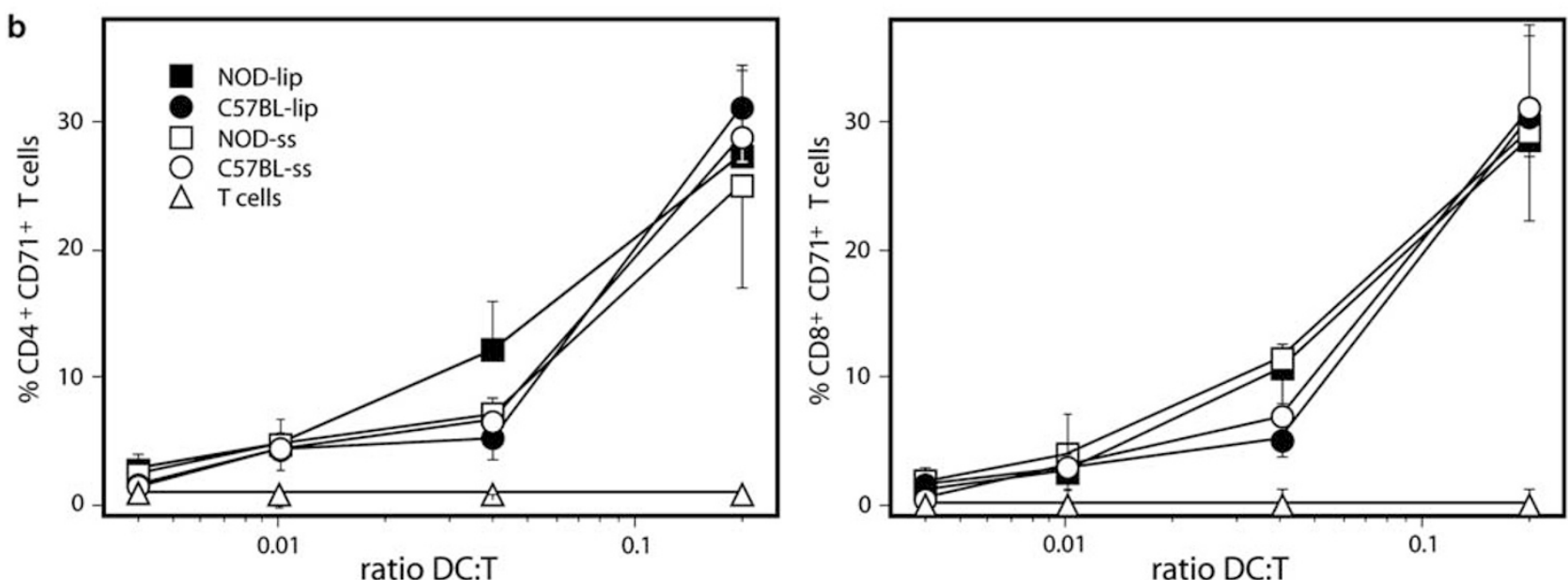

Figure 4 Phenotype and T-cell stimulatory capacity of DC isolated from spleens of treated or untreated NOD and C57BL mice. (a) Isolated $\mathrm{CD}_{11 \mathrm{C}^{+}}$cells showed a normal mature DC phenotype. Histograms display the marker expression by the autoMACS-isolated DC population. The gray line represents the negative isotype control, the thin black line the marker expression by cells isolated from untreated mice and the thick black line the expression pattern of cells isolated from treated mice at day 7 after treatment. (b) The stimulation capacity of isolated DC was the same in NOD and C57BL mice irrespectively of whether DC were derived from treated or untreated mice. Stimulation of $\mathrm{CD}^{+}$and $\mathrm{CD}^{+}$cells was measured as a percentage of cells that have upregulated expression of transferrin-receptor (CD71) on their surface. Representative histograms (in a) and average values \pm s.e.m. (in b) of three separate pools from two independent experiments for each group are shown in the figure.

of $B$ cells started to decline and the cells had completely disappeared by day 7 . Interestingly, B cells seemed to require other conditions to infiltrate the pancreas again, as they did not reappear by day 28 but returned to the pancreas much later, that is, at day 49 post-treatment (data not shown).

\section{Discussion}

In this study, we bring to light three important findings related to the role of DC and $\mathrm{M} \phi$ in the development of insulitis and diabetes in the NOD mouse model.

First, a short-term treatment with lip- $\mathrm{CL}_{2} \mathrm{MDP}$ given in the stage of a progressing peri-insulitis (8 weeks of age) was sufficient to induce a significant decline in the number of $\mathrm{M} \phi$ and DC in the islet vicinity for a period of at least 3 weeks in NOD mice. Second, the loss of DC and $\mathrm{M} \phi$ from the pancreas revealed an essential role of these cells in the local recruitment and retention of lymphocytes. Lymphocyte infiltrations dissolved completely when the

Figure 3 Immunohistochemical analysis of the distribution of $\mathrm{CD} 11 \mathrm{c}^{+}$and $\mathrm{F} 4 / 80^{+}$cells in the NOD spleen at different time points after lip-CL ${ }_{2}$ MDP treatment. (a and b) Distribution of cells before the treatment (SS). (c and d) At day 2 after injection, CD11c ${ }^{+}$and F4/80 ${ }^{+}$ cells were completely depleted from the red pulp. (e and f) The return of cells is evident already 4 days after injection (lip d4). (g and $\mathbf{h}$ ) Normal distribution of $\mathrm{CD} 11 \mathrm{c}^{+}$and $\mathrm{F} 4 / 80^{+}$cells was observed from days 14 and 7 after the depletion, respectively. Symbols depicted indicate: r: red pulp, w: white pulp. 

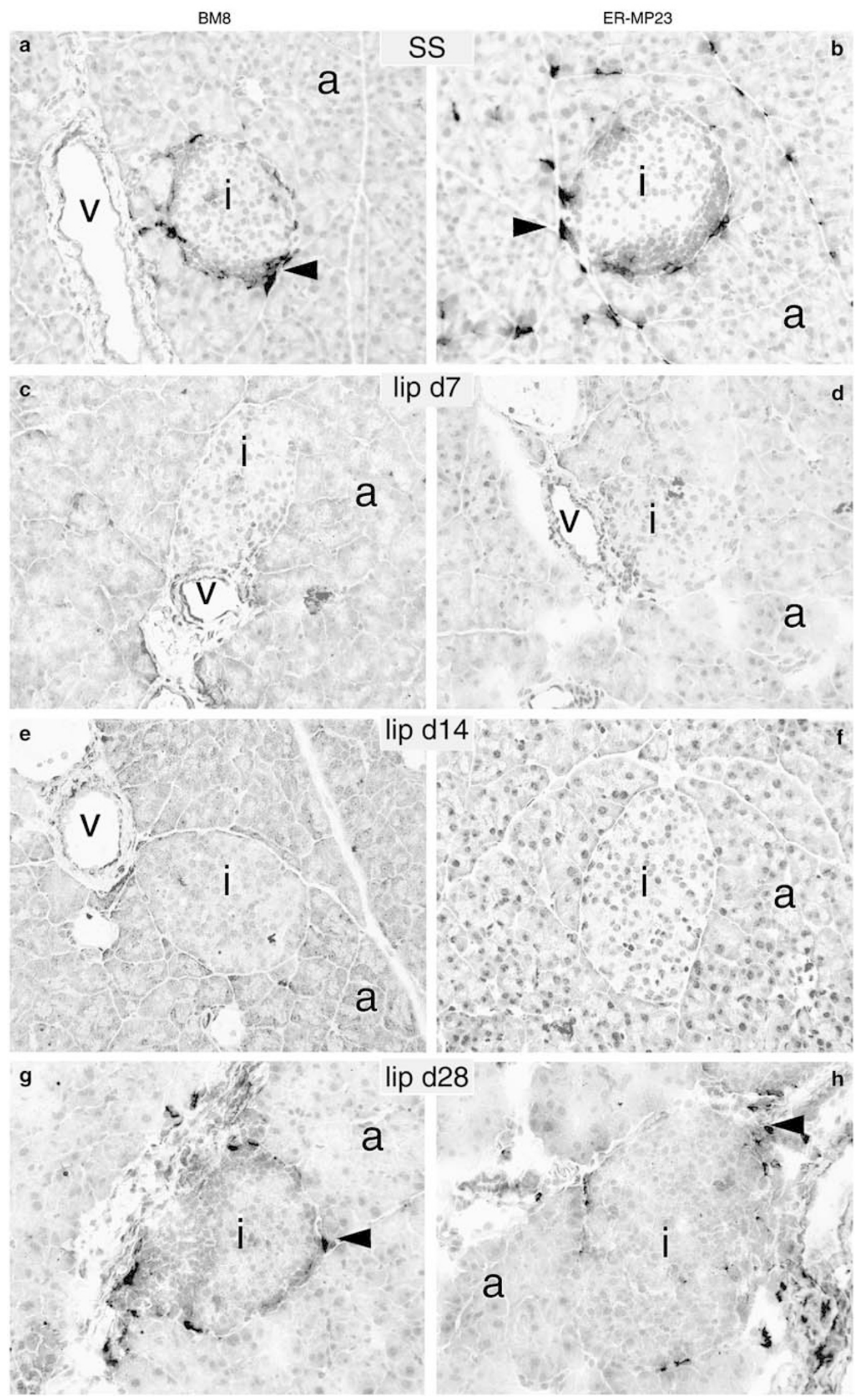

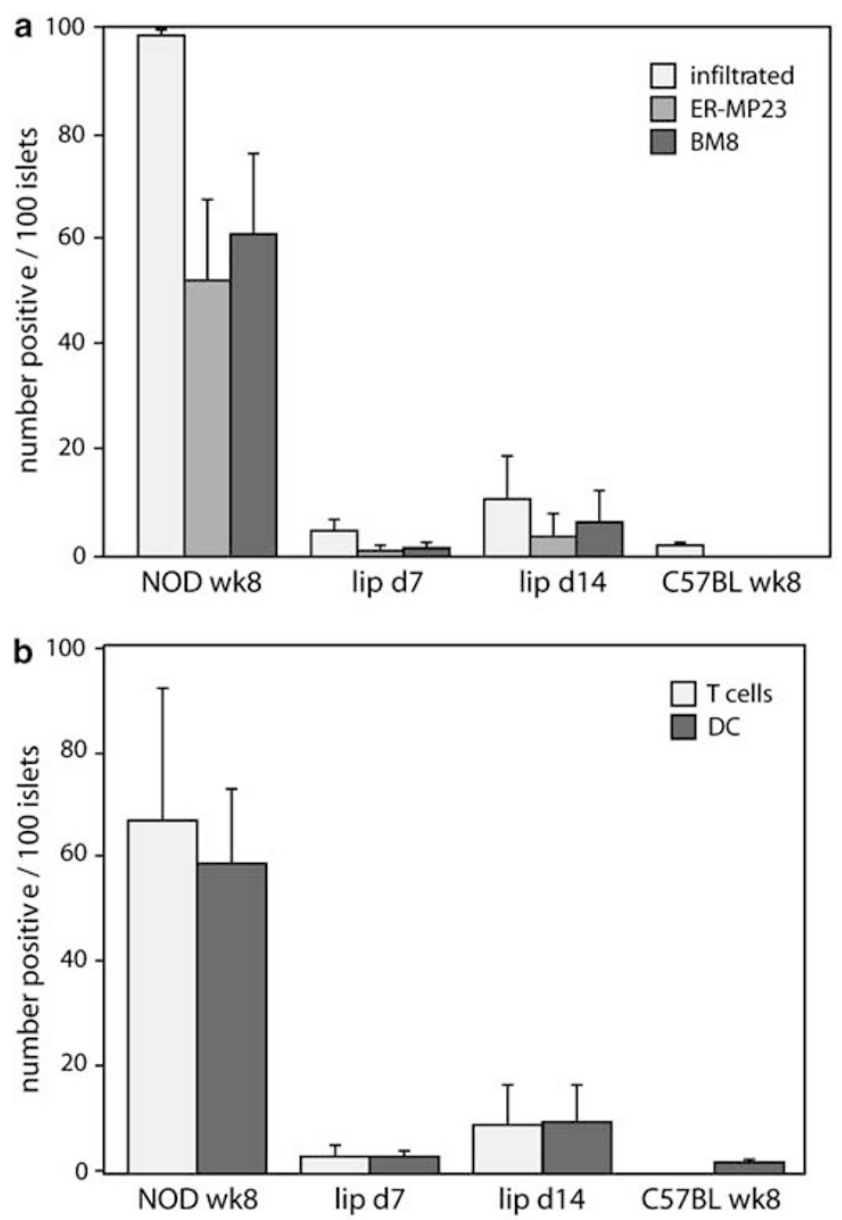

Figure 6 Differential analysis of the islets with inflammatory infiltrations before and after lip- $\mathrm{CL}_{2} \mathrm{MDP}$ treatment. The treatment significantly decreased the frequency of islets infiltrated with $\mathrm{M} \phi$ and DC, which directly correlated to the disappearance of lymphocytes from the pancreas. (a) Correlation of the $\mathrm{M} \phi$ presence with islet infiltration at different time points. Light-gray bars represent the percentage of infiltrated islets, determined by morphological examination of glucagon-positive islets. Dark-gray bars show the frequency of islets associated with ER-MP $23^{+} \mathrm{M} \phi$ and black bars represent values for the $\mathrm{BM}^{+} \mathrm{M} \phi$; before the treatment, at different post-treatment time points and in untreated C57BL mice. (b) Correlation of a DC loss with the departure of T cells, in the pancreas of treated mice. Black bars represent the percentage of islets that contained $\mathrm{CD} 11 \mathrm{c}^{+} \mathrm{DC}$ and light-gray bars the percentage of islets that contained $\mathrm{T}\left(\mathrm{CD}^{+}\right)$cells, like in (a) All bars show the average value ( \pm s.e.m.) calculated from three or four mice per group for each strain and each time point.

$\mathrm{DC} / \mathrm{M} \phi$ pool was absent and reappeared only upon return of $\mathrm{DC}$ and $\mathrm{M} \phi$ in close proximity to the endocrine tissue. Third, the depletion of the DC and $\mathrm{M} \phi$ did not happen concomitantly in the pancreas and in the circulatory compartment. Monocytes, DC and $\mathrm{M} \phi$ were depleted and rapidly returned to the circulation and the spleen within 1 week with similar kinetics in NOD and control mice, whereas in the pancreas their disappearance started at the end of the first week. Furthermore, in line with the observed changes in the pancreas, the diabetes onset and incidence were strongly delayed and decreased, respectively, after short-term lip- $\mathrm{CL}_{2} \mathrm{MDP}$ treatment of NOD mice at 8 weeks of age.

It is well known that an i.p. injection of lip$\mathrm{CL}_{2} \mathrm{MDP}$ depletes $\mathrm{M} \phi$ from the spleen, peritoneal cavity and the omentum, ${ }^{20}$ but the pancreas has not been included in such previous depletion studies. Our study shows that i.p. injections of lip- $\mathrm{CL}_{2} \mathrm{MDP}$ also influence the accumulation of monocytes, $\mathrm{M} \phi$ and DC in the pancreas. Remarkably, however, when we compared the effects of depletion in the pancreas with that of the spleen/circulation, we observed different kinetics of disappearance and return of the phagocytes: DC and $\mathrm{M} \phi$ took a week longer to disappear from the pancreas. Unfortunately, we cannot readily explain these differential disappearance patterns.

The return of mature monocytes to the circulation and the spleen preceded the return of DC and $\mathrm{M} \phi$. This supports the view that spleen antigen presenting cells originate from blood monocytes. Treatment with lip-CL ${ }_{2}$ MDP ineffectively depletes phagocytes in the connective tissue. ${ }^{21}$ Indeed, the delayed disappearance of pancreatic DC and $\mathrm{M} \phi$ upon treatment strongly suggests that liposomes do not reach these phagocytes directly. Instead, it is more likely that the natural turnover of the cells, under conditions when the precursors might be lacking, causes their decline. In line with this, unlike in the spleen where we observed nonviable pycnotic cells, probably resembling the cells that engulfed liposomes and died of apoptosis, ${ }^{18}$ we did not observe any apoptotic cells in the pancreas.

It is, however, difficult to understand why monocytes did not rapidly replenish DC and $\mathrm{M} \phi$ in the pancreas, like they do in other target organs such as the spleen and liver, since the disappearance of pancreas DC and $\mathrm{M} \phi$ started when monocytes were back in the circulation.

One possible explanation is that the pancreas DC and $\mathrm{M} \phi$ might originate from other precursors than those found in the circulation. The origin of pancreas resident $\mathrm{M} \phi$ and DC is not known. They might develop from intraorgan precursors, like in the skin, ${ }^{22}$ or from precursors that reside in the vicinity of the pancreas. In this context, it is noteworthy that i.p. application of lip- $\mathrm{CL}_{2} \mathrm{MDP}$ to

Figure 5 Prolonged disappearance of $\mathrm{M} \phi$ from the pancreas of NOD mice after lip-CL ${ }_{2} \mathrm{MDP}$ treatment. (a and b) Peri- and intra-islet infiltrates from untreated 8-week-old NOD mice contain $\mathrm{BM}{ }^{+}$and ER-MP23 ${ }^{+} \mathrm{M} \phi$. Both subsets of $\mathrm{M} \phi$ were also found scattered

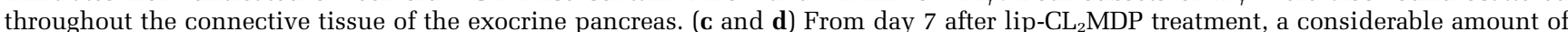
resident $\mathrm{M} \phi$ had disappeared from the endocrine pancreas. (e and $\mathbf{f}$ ) At day 14, the pancreas is found similarly devoid of $\mathrm{M} \phi$ as at day 7 . (g and h) M $\phi$ were again detectable at day 28 after the lip- $\mathrm{CL}_{2} \mathrm{MDP}$ treatment and present in the close proximity of pancreatic islets. Symbols depicted indicate: a: exocrine acini, i: islet and v: vessel. 

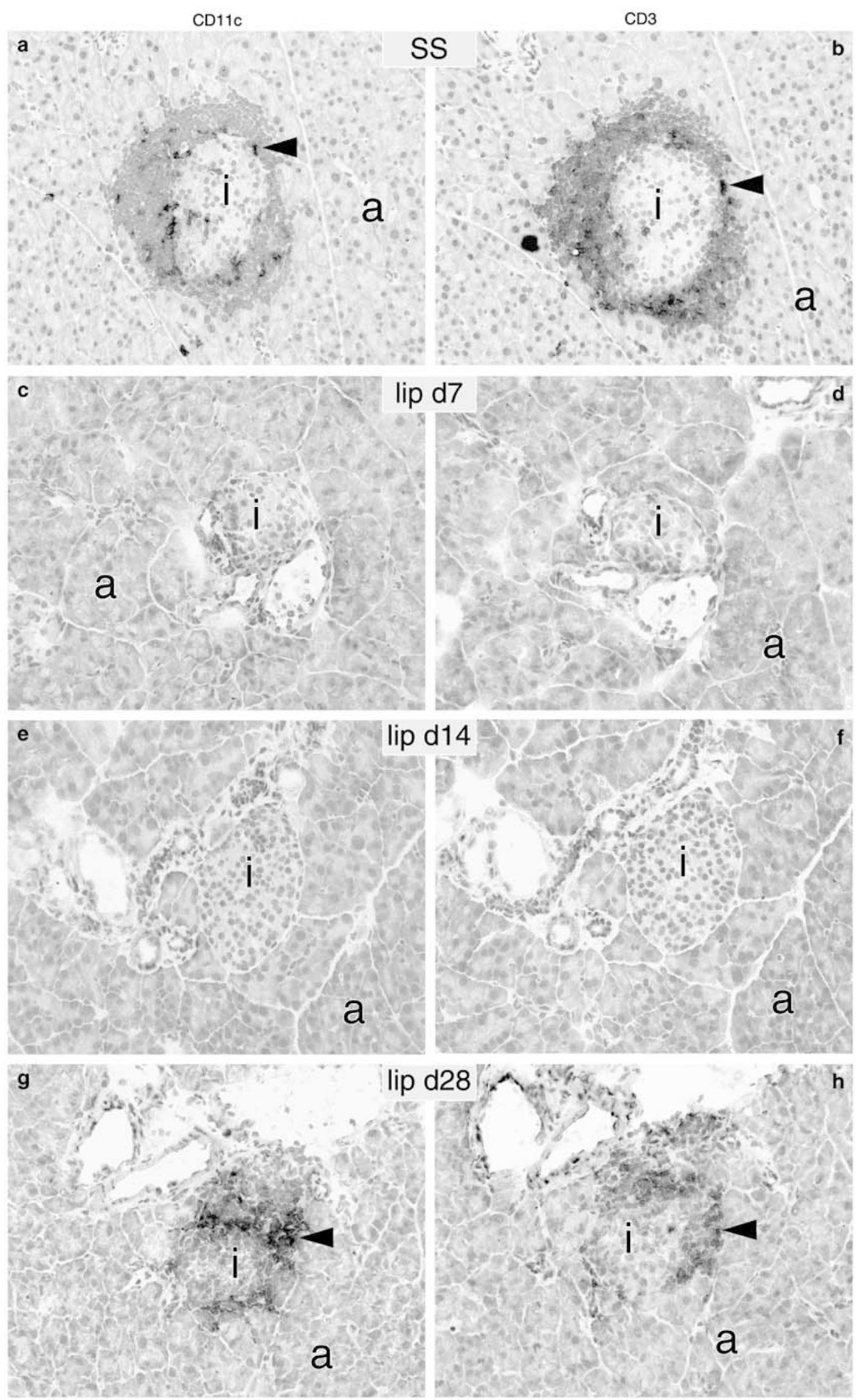
rats induced a depletion of $\mathrm{M} \phi$ in the peritoneum and omentum within 2 days, but the repopulation of the omental $\mathrm{M} \phi$ was not seen within the next 23 days. ${ }^{23}$ This 'postponed' pattern of reappearance overlaps with the here described slow pattern of reappearance of $\mathrm{M} \phi$ and $\mathrm{DC}$ in the pancreas and this might either point to the omentum as a source of precursors for pancreas DC and $\mathrm{M} \phi$, or to a shared precursor of omental and pancreas DC and $\mathrm{M} \phi$. Further investigation is needed to evaluate whether such peripheral precursors might be affected by the i.p. lip- $\mathrm{CL}_{2} \mathrm{MDP}$ treatment more extensively than the circulating monocytes.

Alternatively, the lip- $\mathrm{CL}_{2} \mathrm{MDP}$ treatment interrupts the continuous influx of monocytes into the pancreas for several days and thereby possibly the production of chemoattractants for other inflammatory cells. ${ }^{24,25}$ In this case, the dynamic inflammatory process might be transiently interrupted and subsequently slowly restored, similarly to what has been demonstrated for lymphotoxin. ${ }^{26}$

Importantly, we observed an apparent relation of the retention of lymphocytes to the presence of periislet DC and $\mathrm{M} \phi$. In an induced diabetes model, the administration of streptozotocin to $\mathrm{C} 57 \mathrm{BL} / 6$ mice led to an accumulation of DC in the pancreas, followed by an enhanced expression of adhesion molecules on the pancreatic endothelium and an increased adherence and infiltration of lymphocytes. $^{27} \mathrm{~A}$ role for DC in the accumulation of lymphocytes in the pancreas has been suggested previously as the elimination of phagocytic cells by lip-CL ${ }_{2} \mathrm{MDP}$ reduced the lymphocytic infiltration of transplanted fetal pig pancreas xenografts in NOD mice ${ }^{28}$ Furthermore, lymphocyte adhesion and infiltration decreased upon silica-mediated depletion of the $\mathrm{M} \phi$ additionally suggesting that the $\mathrm{M} \phi$ were also involved in the recruitment of lymphocytes. $^{29,30}$ This process is not only specific for pancreas, the loss of marginal zone $\mathrm{M} \phi$ as the result of chronic Leishmania infection severely abrogated normal trafficking of lymphocytes into the white pulp of the spleen. ${ }^{31}$

DC and $\mathrm{M} \phi$ possibly act by inducing the addressins VCAM-1, MAdCAM-1 and ICAM-1 on the pancreatic endothelium. ${ }^{5,32,33}$ However, the responsible $\mathrm{M} \phi$ or DC-derived factor that initiates the infiltration and maintenance of lymphocytes in the pancreas has not been identified thus far. The examination of expression of various chemokines in NOD pancreases prior to $\mathrm{M} \phi$ and/or DC accumulation and during the course of early and advanced insulitis did not clearly indicate a single chemokine responsible for the recruitment of lymphocytes. ${ }^{34-38}$ Silencing chemokine or chemokine receptor expression, or preventing ligand-receptor interaction by neutralizing antibody treatment, abrogated or delayed the development of diabetes in NOD mice ${ }^{35-38}$ However, these approaches failed to block lymphocytic insulitis completely. Therefore, the investigation of potential candidate chemokines and adhesion molecules responsible for lymphocyte recruitment that are directly DC and $\mathrm{M} \phi$-derived, or induced in the surrounding epithelial cells by activated DC and $\mathrm{M} \phi$, needs further attention.

In conclusion, a depletion of DC and $\mathrm{M} \phi$ via a regimen of two injections of lip- $\mathrm{CL}_{2} \mathrm{MDP}$ in the stage of a progressing peri-insulitis (at 8 weeks of age) was sufficient to clear DC and $\mathrm{M} \phi$ almost completely from the pancreas, and to delay the reappearance of these cells considerably. The presence of DC and $\mathrm{M} \phi$ in the pancreas dictated the presence of lymphocytes, which should be taken into account for developing possible new treatments for diabetes.

\section{Acknowledgements}

We acknowledge the contribution of B Beukenkamp and $M$ Aoulad-Ahmed to this study with their technical assistance. In addition, we thank Tar van Os for his important contribution in preparing the figures. The investigation presented here was made possible due to the financial support from the Dutch Diabetes Research Foundation (Grant 96.606) and grants from the European committee (QLRT-199900276 - 'MONODIAB').

\section{References}

1 Rosmalen JG, Leenen PJ, Pelegri C, et al. Islet abnormalities in the pathogenesis of autoimmune diabetes. Trends Endocrinol Metab 2002;13:209-214.

2 Charre S, Rosmalen JG, Pelegri C, et al. Abnormalities in dendritic cell and macrophage accumulation in the pancreas of nonobese diabetic (NOD) mice during the early neonatal period. Histol Histopathol 2002;17: 393-401.

3 Jansen A, Homo_Delarche F, Hooijkaas H, et al. Immunohistochemical characterization of monocytesmacrophages and dendritic cells involved in the initiation of the insulitis and beta-cell destruction in NOD mice. Diabetes 1994;43:667-675.

Figure 7 The presence of T cells correlated directly with the DC in the pancreas of NOD mice. (a and b) Before the treatment with lip$\mathrm{CL}_{2} \mathrm{MDP}$ DC were found in the close proximity of T cells as judged by the immunohistochemical analysis of serial sections of the NOD mouse pancreas. (c and d) At day 7 after the treatment, DC had disappeared from the pancreas and T cells as well. (e and f) Islets that were free of DC were also free of lymphocytic accumulations in the pancreas, at day 14 after the treatment. (g and h) At 28 days after the treatment, return of DC was found in few islets, paralleled by the return of T cells. Symbols depicted indicate: a: exocrine acini and i: islet. 
4 Rosmalen JG, Martin T, Dobbs C, et al. Subsets of macrophages and dendritic cells in nonobese diabetic mouse pancreatic inflammatory infiltrates: correlation with the development of diabetes. Lab Invest 2000;80: 23-30.

5 Yang XD, Sytwu HK, McDevitt HO, et al. Involvement of beta 7 integrin and mucosal addressin cell adhesion molecule-1 (MAdCAM-1) in the development of diabetes in obese diabetic mice. Diabetes 1997;46: 1542-1547.

6 Fabien N, Bergerot I, Orgiazzi J, et al. Lymphocyte function associated antigen-1, integrin alpha 4, and L-selectin mediate T-cell homing to the pancreas in the model of adoptive transfer of diabetes in NOD mice. Diabetes 1996;45:1181-1186.

7 Hutchings P, O'Reilly L, Parish NM, et al. The use of a non-depleting anti-CD4 monoclonal antibody to reestablish tolerance to beta cells in NOD mice. Eur J Immunol 1992;22:1913-1918.

8 Lee KU, Amano K, Yoon JW. Evidence for initial involvement of macrophage in development of insulitis in NOD mice. Diabetes 1988;37:989-991.

9 Jun HS, Santamaria P, Lim HW, et al. Absolute requirement of macrophages for the development and activation of beta-cell cytotoxic CD8+ T-cells in T-cell receptor transgenic NOD mice. Diabetes 1999;48:34-42.

10 Jun HS, Yoon CS, Zbytnuik L, et al. The role of macrophages in T cell-mediated autoimmune diabetes in nonobese diabetic mice. J Exp Med 1999;189: 347-358.

11 Leenen PJ, Radosevic K, Voerman JS, et al. Heterogeneity of mouse spleen dendritic cells: in vivo phagocytic activity, expression of macrophage markers, and subpopulation turnover. J Immunol 1998; 160:2166-2173.

12 Claassen E. Detection, localization and kinetics of immunomodulating liposomes in vivo. Res Immunol 1992;143:235-241.

13 Van Rooijen N, Sanders A. Liposome mediated depletion of macrophages: mechanism of action, preparation of liposomes and applications. J Immunol Methods 1994;174:83-93.

14 Jansen A, Rosmalen JG, Homo-Delarche F, et al. Effect of prophylactic insulin treatment on the number of ERMP23+ macrophages in the pancreas of NOD mice. Is the prevention of diabetes based on beta-cell rest? J Autoimmun 1996;9:341-348.

15 Nikolic T, Bruijn MF, Lutz MB, et al. Developmental stages of myeloid dendritic cells in mouse bone marrow. Int Immunol 2003;15:515-524.

16 Sunderkotter C, Nikolic T, Dillon MJ, et al. Subpopulations of mouse blood monocytes differ in maturation stage and inflammatory response. J Immunol 2004;172: 4410-4417.

17 Geissmann F, Jung S, Littman DR. Blood monocytes consist of two principal subsets with distinct migratory properties. Immunity 2003;19:71-82.

18 van Rooijen N, Sanders A, van den Berg TK. Apoptosis of macrophages induced by liposome-mediated intracellular delivery of clodronate and propamidine. J Immunol Methods 1996;193:93-99.

19 van Rooijen N, Kors N, Kraal G. Macrophage subset repopulation in the spleen: differential kinetics after liposome-mediated elimination. J Leukoc Biol 1989;45: 97-104.

$20 \mathrm{Zhu} \mathrm{H}$, Naito $\mathrm{M}$, Umezu $\mathrm{H}$, et al. Macrophage differentiation and expression of macrophage colony- stimulating factor in murine milky spots and omentum after macrophage elimination. J Leukoc Biol 1997;61: 436-444.

21 van Rooijen N, Sanders A. Elimination, blocking, and activation of macrophages: three of a kind? J Leukoc Biol 1997;62:702-709.

22 Merad M, Manz MG, Karsunky H, et al. Langerhans cells renew in the skin throughout life under steady-state conditions. Nat Immunol 2002;3:11351141.

23 Biewenga J, van der Ende MB, Krist LF, et al. Macrophage depletion in the rat after intraperitoneal administration of liposome-encapsulated clodronate: depletion kinetics and accelerated repopulation of peritoneal and omental macrophages by administration of Freund's adjuvant. Cell Tissue Res 1995;280: 189-196.

24 Penna G, Vulcano M, Sozzani S, et al. Differential migration behavior and chemokine production by myeloid and plasmacytoid dendritic cells. Hum Immunol 2002;63:1164-1171.

25 Caux C, Vanbervliet B, Massacrier C, et al. Regulation of dendritic cell recruitment by chemokines. Transplantation 2002;73(Suppl):S7-S11.

$26 \mathrm{Wu} \mathrm{Q}$, Salomon B, Chen $\mathrm{M}$, et al. Reversal of spontaneous autoimmune insulitis in nonobese diabetic mice by soluble lymphotoxin receptor. J Exp Med 2001;193:1327-1332.

27 Ludewig B, Odermatt B, Landmann S, et al. Dendritic cells induce autoimmune diabetes and maintain disease via de novo formation of local lymphoid tissue. J Exp Med 1998;188:1493-1501.

28 Fox A, Koulmanda M, Mandel TE, et al. Evidence that macrophages are required for T-cell infiltration and rejection of fetal pig pancreas xenografts in nonobese diabetic mice. Transplantation 1998;66: 1407-1416.

29 Ludwig R, Kretschmer M, Caspar G, et al. In vivo microscopy of murine islets of Langerhans: increased adhesion of transferred lymphocytes to islets depends on macrophage-derived cytokines in a model of organspecific insulitis. Immunology 1999;98:111-115.

30 Kusterer K, Ludwig R, Hochschulz P, et al. Macrophage and lymphocyte homing in experimental diabetes. Exp Clin Endocrinol Diabetes 1999;107(Suppl 3): S102-S107.

31 Engwerda CR, Ato M, Cotterell SE, et al. A role for tumor necrosis factor-alpha in remodeling the splenic marginal zone during Leishmania donovani infection. Am J Pathol 2002;161:429-437.

32 Baron JL, Reich EP, Visintin I, et al. The pathogenesis of adoptive murine autoimmune diabetes requires an interaction between alpha 4-integrins and vascular cell adhesion molecule-1. J Clin Invest 1994;93:17001708.

33 Moriyama H, Yokono K, Amano K, et al. Induction of tolerance in murine autoimmune diabetes by transient blockade of leukocyte function-associated antigen-1/ intercellular adhesion molecule-1 pathway. J Immunol 1996;157:3737-3743.

34 Cameron MJ, Arreaza GA, Grattan M, et al. Differential expression of CC chemokines and the CCR5 receptor in the pancreas is associated with progression to type I diabetes. J Immunol 2000;165:1102-1110.

35 Frigerio S, Junt T, Lu B, et al. Beta cells are responsible for CXCR3-mediated T-cell infiltration in insulitis. Nat Med 2002;8:1414-1420. 
36 Carvalho-Pinto C, Garcia MI, Gomez L, et al. Leukocyte attraction through the CCR5 receptor controls progress from insulitis to diabetes in non-obese diabetic mice. Eur J Immunol 2004;34: 548-557.

37 Kutlu B, Darville MI, Cardozo AK, et al. Molecular regulation of monocyte chemoattractant protein-1 expression in pancreatic beta-cells. Diabetes 2003;52: 348-355.

38 Chen MC, Proost P, Gysemans C, et al. Monocyte chemoattractant protein-1 is expressed in pancreatic islets from prediabetic NOD mice and in interleukin-1 beta-exposed human and rat islet cells. Diabetologia 2001;44:325-332. 